\title{
Impaired regulation of force and firing pattern of single motor units in patients with spasticity
}

\author{
ANNELISE ROSENFALCK AND STEEN ANDREASSEN \\ From the Institute of Electronic Systems, Aalborg University Center, Aalborg, Denmark
}

SUMMARY Patients with spasticity were unable to maintain a constant force of the anterior tibial muscle. The force at maximal effort was reduced to less than $40 \%$ of normal, partly because motor units fired at a reduced rate even at high levels of contraction. Force and instantaneous frequency fluctuated slowly. The fast regulation of the firing rate, which characterises normal muscle, was absent. The variation between successive intervals was less than normal and the serial correlation coefficient between intervals increased.

Changes in the firing pattern and in the recruitment order of single motor units have been claimed to be characteristic of central motor lesions. A reduced firing rate was found in Parkinsonism $^{1}$ and in patients with upper motor neuron lesions. ${ }^{2-5}$ Findings with respect to the firing pattern are conflicting. $\mathrm{Kranz}^{2}{ }^{3}$ found a slight decrease in the variability of the intervals in most motor units. A similar pattern was described by Freund et $a l^{6}$ in patients with cerebellar lesions but only one third of the motor units were reported to show the same characteristic deviations from the normal firing pattern. Contrary to this they found increased variability of the intervals and negative serial correlation to be typical for patients with spastic hemipareses. The orderly recruitment of motor units according to size ${ }^{7-10}$ was reported to be disturbed in spastic patients. ${ }^{11} 12$ In the study presented in this report the firing pattern of single motor units in the anterior tibial muscle was investigated in 10 patients with spasticity.

\section{Patients}

The patients (table 1) were grouped as follows: four patients had a spastic hemiparesis due to a cerebral lesion (group $\mathbf{P}_{1}$ ). Six patients had spasticity due to multiple sclerosis; three had clinical findings suggesting cerebral or cerebellar

Address for reprint requests: A Rosenfalck, Institute of Electronic Systems, Aalborg University Center, Box 159, DK-9100 Aalborg, Denmark.

Accepted 1 April 1980 involvement (group $\mathbf{P}_{2}$ ), the other three had mainly spinal involvement (group $\mathbf{P}_{3}$ ).

All but one of the 10 patients were able to produce a voluntary contraction of the anterior tibial muscle and to grade the contraction. There was no activity at rest after suitable positioning. The torque at the ankle at maximal effort $\left(\mathrm{T}_{\max }\right)$ was less than $40 \%$ of that in control subjects, matched for body height, sex and age (table 1). The resistance of the anterior tibial muscle to passive stretch was increased in six patients. In seven patients the reflexogenic zone of knee or heel jerks was increased, and three had clonus.

\section{Methods}

The method of recording and the definition of the statistical parameters were described by Andreassen and Rosenfalck. ${ }^{13}$ In brief: The action potentials from single motor units were recorded from the anterior tibial muscle by selective bipolar electrodes placed intramuscularly. The leading-off surfaces of the electrodes were side holes in a pair of insulated wires. ${ }^{14}$

The wires were threaded through the muscle such that they could be adjusted to lie close to active fibres and moved to fibres of different motor units. The temperature of the skin overlying the muscle was maintained at $34-36^{\circ} \mathrm{C}$. The patients were asked to dorsiflex the ankle and to maintain a constant level of force measured as the torque around the ankle joint. The torque was monitored on a meter suspended in front of the 907 
Table 1

\begin{tabular}{|c|c|c|c|c|c|c|c|c|c|c|c|}
\hline Group & Patient & $\begin{array}{l}\text { Age } \\
(y r)\end{array}$ & $\begin{array}{l}\text { Duration } \\
\text { of disease }\end{array}$ & $\begin{array}{l}\text { Daily } \\
\text { meditation }\end{array}$ & $\begin{array}{l}T_{\max } \\
(N m)\end{array}$ & $\begin{array}{l}T_{\max } \\
(\%)\end{array}$ & $\begin{array}{l}\text { Normal } \\
(\mathrm{Nm})\end{array}$ & $n$ & $\begin{array}{l}\text { Ankle } \\
\text { jerk }\end{array}$ & $\begin{array}{l}\text { Knee } \\
\text { jerk }\end{array}$ & $\begin{array}{l}\text { Resistance } \\
\text { to stretch }\end{array}$ \\
\hline $\begin{array}{l}\mathbf{P}_{1} \\
\mathbf{P}_{1} \\
\mathbf{P}_{1} \\
\mathbf{P}_{1}\end{array}$ & $\begin{array}{l}\text { MH } \\
\text { EP } \\
\text { AP } \\
\text { IN }\end{array}$ & $\begin{array}{l}59 \text { o } \\
72 \text { 울 } \\
71 \text { o } \\
38 \text { 우 }\end{array}$ & $\begin{array}{l}7 \text { days } \\
40 \text { days } \\
27 \text { days } \\
16 \text { years }\end{array}$ & $\begin{array}{l}6 \mathrm{mg} \text { diazepan } \\
\text { None } \\
\text { None } \\
10 \mathrm{mg} \text { diazepan and } \\
\text { antiepileptic drugs }\end{array}$ & $\begin{array}{c}7 \cdot 5 \\
5 \cdot 0 \\
2 \cdot 5 \\
\text { None }\end{array}$ & $\begin{array}{l}14 \\
14 \\
15 \\
-\end{array}$ & $\begin{array}{l}54 \\
34 \\
47 \\
-\end{array}$ & $\begin{array}{r}15 \\
19 \\
15 \\
6\end{array}$ & $\begin{array}{l}0 \\
0 \\
+ \\
++\end{array}$ & $\begin{array}{l}0 \\
0 \\
+ \\
++\end{array}$ & $\begin{array}{l}0 \\
0 \\
0 \\
++\end{array}$ \\
\hline $\begin{array}{l}\mathbf{P}_{2} \\
\mathbf{P}_{2} \\
\mathbf{P}_{2}\end{array}$ & $\begin{array}{l}\text { IB } \\
\text { GA } \\
\text { PG }\end{array}$ & $\begin{array}{l}56 \text { 울 } \\
48 \text { ㅇ } \\
62 \text { वै }\end{array}$ & $\begin{array}{c}2 \text { years } \\
6 \text { months } \\
3 \text { years }\end{array}$ & $\begin{array}{l}\text { None } \\
\text { None } \\
\text { None }\end{array}$ & $\begin{array}{r}15 \cdot 0 \\
4 \cdot 5 \\
13 \cdot 5\end{array}$ & $\begin{array}{l}41 \\
12 \\
31\end{array}$ & $\begin{array}{l}36 \\
37 \\
44\end{array}$ & $\begin{array}{l}19 \\
24 \\
14\end{array}$ & $\begin{array}{l}+ \\
0 \\
-\end{array}$ & $\begin{array}{l}+ \\
0 \\
+\end{array}$ & $\begin{array}{l}+ \\
+ \\
+\end{array}$ \\
\hline $\begin{array}{l}\mathbf{P}_{3} \\
\mathbf{P}_{3} \\
\mathbf{P}_{3}\end{array}$ & $\begin{array}{l}\text { SG } \\
\text { NF } \\
\text { BA }\end{array}$ & $\begin{array}{l}450 \\
48 \text { ํㅜ } \\
49 \text { ํ }\end{array}$ & $\begin{array}{l}8 \text { years } \\
3 \text { years } \\
9 \text { years }\end{array}$ & $\begin{array}{l}\text { Corticotrophine } \\
\text { Corticotrophine } \\
15 \mathrm{mg} \text { baclofen }\end{array}$ & $\begin{array}{r}12 \cdot 5 \\
17 \cdot 0 \\
5 \cdot 5\end{array}$ & $\begin{array}{l}16 \\
28 \\
15\end{array}$ & $\begin{array}{l}78 \\
62 \\
37\end{array}$ & $\begin{array}{l}18 \\
12 \\
18\end{array}$ & $\begin{array}{l}++ \\
++ \\
+\end{array}$ & $\begin{array}{l}+ \\
+ \\
+\end{array}$ & $\begin{array}{l}0 \\
+ \\
+\end{array}$ \\
\hline
\end{tabular}

$T_{\max }$ : Torque at maximal effort. Normal: Torque at maximal effort for normal subjects matched for body height, sex and age from Asmussen and Heebøll-Nielsen (1961). $\mathrm{n}$ is the number of motor units investigated. 0 normal; + increased reflexogenic zone, increased resistance to plantar flexion; ++ increased tone and clonus; - absent tendon jerks.

patient. Before the electrodes were inserted the patients were instructed to maintain a constant torque and the torque $\left(T_{\max }\right)$ which the patient could exert at maximal voluntary effort was determined (table 1). After insertion of the electrodes, the EMG and the torque were recorded over 10-20 periods of one to four minutes on an FM-tape recorder for analysis. From each recording a $20 \mathrm{~s}$ period was selected by: (i) minimum variation in torque, and (ii) uninterrupted firing of motor unit potentials. The data were analysed off-line. ${ }^{13}$

\section{Analysis}

One hundred and twenty-two recordings from the 10 patients were selected for analysis. One third of the recordings had action potentials from two to three motor units. The potentials were classified automatically as belonging to one of the motor units according to their shape and their time of occurrence. This allowed analysis of the firing pattern of 160 different motor units from the 122 recordings. Twelve to 24 motor units were analysed per patient, except in one where six motor units were investigated. In recordings with action potentials from more than one motor unit several potentials coincide in time and superposition potentials are formed. It was therefore impossible to measure each interval in the action potential trains from different motor units without a manual or an automatic classification of the potentials. If an amplitude trigger had been used only about 80 of the 160 motor units in this material could have been analysed.

The patients had difficulty in keeping firing rate and force constant, as noted by Kranz." Therefore the statistical parameters generally used to describe the firing pattern are not adequate. Instead the variability of the intervals was measured by the parameters VAR, VARI and FSD, and the floating serial correlation coefficient FRHO, as described by Andreassen and Rosenfalck. ${ }^{13}$

\section{Results}

Torque and firing frequency The torque exerted at maximal effort was $40 \%$ or less of that exerted by normal subjects matched for body height, sex and age (table 1). The mean firing frequency recorded over $20 \mathrm{~s}$ was lower in the patients with spasticity than in normal subjects. It ranged from 5 to $13 \mathrm{~Hz}$ compared with 6 to $20 \mathrm{~Hz}$ in normals corresponding to mean intervals ranging from 75 to $200 \mathrm{~ms}$ in the
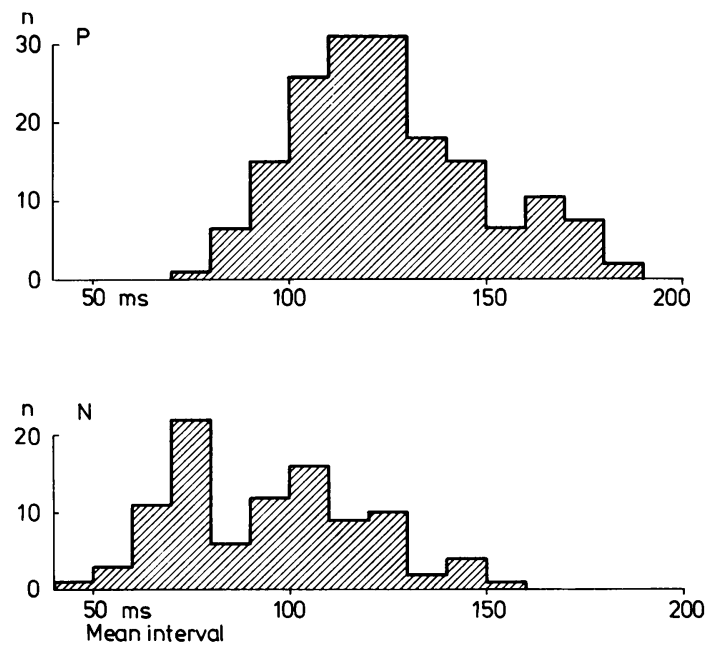

Fig 1 Histograms of mean intervals determined from 160 recordings in patients with spasticity $(P)$ and from 79 recordings in normal subjects $(N)$. 

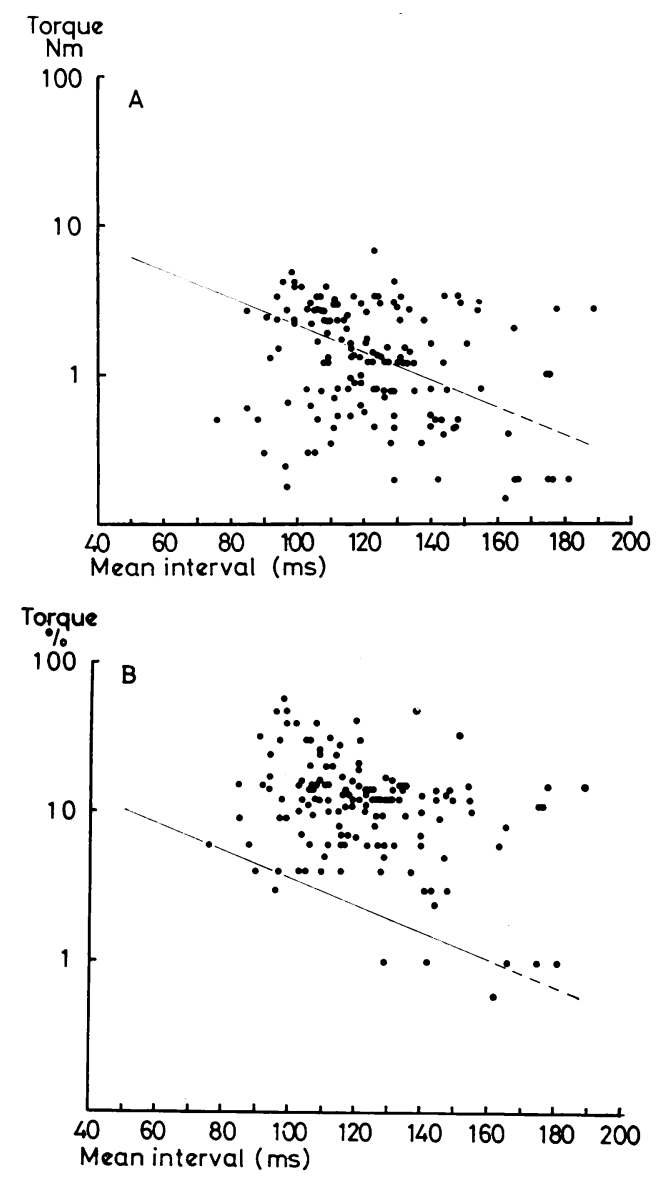

Fig 2 Relation between torque around the ankle joint and mean interval. Ordinate: $A$. Torque $(\mathrm{Nm})$ corrected for body height, age and sex. $60 \mathrm{Nm}$ is the normal value for a $175 \mathrm{~cm}$ high male, 25 years of age. B. Torque (\%) expressed in per cent of that exerted at maximal voluntary effort $\left(T_{m a x}\right.$, table 1, log scale). Abscissa: Mean interval, 147 recordings from single motor units in 9 patients with spasticity. The solid lines in $A$ and $B$ are the regression lines determined from 97 recordings from single motor units in 4 normal subjects. ${ }^{13}$

patients and from 49 to $160 \mathrm{~ms}$ in normal subjects (fig 1). Mean intervals longer than $160 \mathrm{~ms}$ were never encountered in the 97 motor units examined in normal subjects. ${ }^{13}$

The relation between torque and mean interval was plotted with the torque expressed in $\mathrm{Nm}$ (fig $2 \mathrm{~A}$ ), and with the torque expressed as per cent of the torque at maximal effort $\left(T_{\max }\right)$ for each patient (fig 2B). To compare the torque in $\mathrm{Nm}$ in patients and in normal subjects of different body height, sex and age the torques were normalised relative to a maximal torque of $60 \mathrm{Nm}$, which is the normal maximal torque for a 25 year old, $175 \mathrm{~cm}$ high male. When the torque was expressed in $\mathrm{Nm}$ most mean intervals fell within the range found in normal subjects. When the torque was expressed in per cent of the torque at maximal effort $\left(T_{\max }\right)$ for each subject, $97 \%$ of the mean intervals recorded in the patients fell above the regression line for mean intervals determined for normal subjects. Long term fluctuations The patients were unable to maintain an isometric contraction of constant torque although they were given the same feedback as the normal subjects, the torque being displayed on a meter and the EMG by a loudspeaker. Torque and frequency fluctuated slowly (fig 3, P). In two thirds of the 122 recordings from the patients with spasticity the fluctuations in torque were $\pm 5-20 \%$ of the average torque and in one third $20-80 \%$ of the average torque. The fluctuations in torque followed the fluctuations in frequency after a delay of $100 \mathrm{~ms}-500 \mathrm{~ms}$. The fluctuations in instantaneous frequency were similar in different motor units recorded simultaneously (fig 4).

Short term variations The variability between successive interspike intervals was smaller in the patients with spasticity than in the normal subjects (fig 3 ). In the normal subjects a long interval was usually followed by a short and vice versa corresponding to a negative serial correlation. In the patients with spasticity a short interval was usually followed by a short, and a long interval by a long, corresponding to a positive serial correlation (figs 3 and 4 ). The

Table 2 Short term variation VAR and floating serial correlation coefficient FRHO between successive intervals

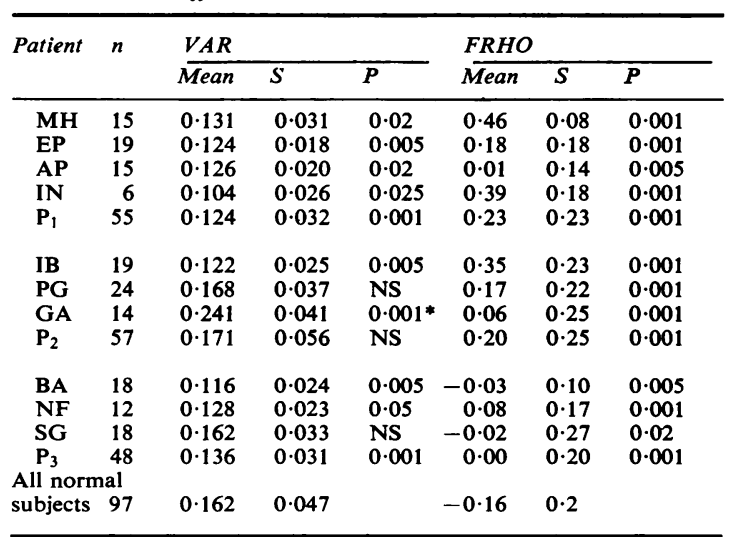

Mean and standard deviation (S) of VAR and FRHO for the $n$ motor units recorded in each patient and in the normal subjects. $P$ is the significance of deviation of the mean from the mean in the normal subjects (NS = not significant)

*VAR greater than normal 


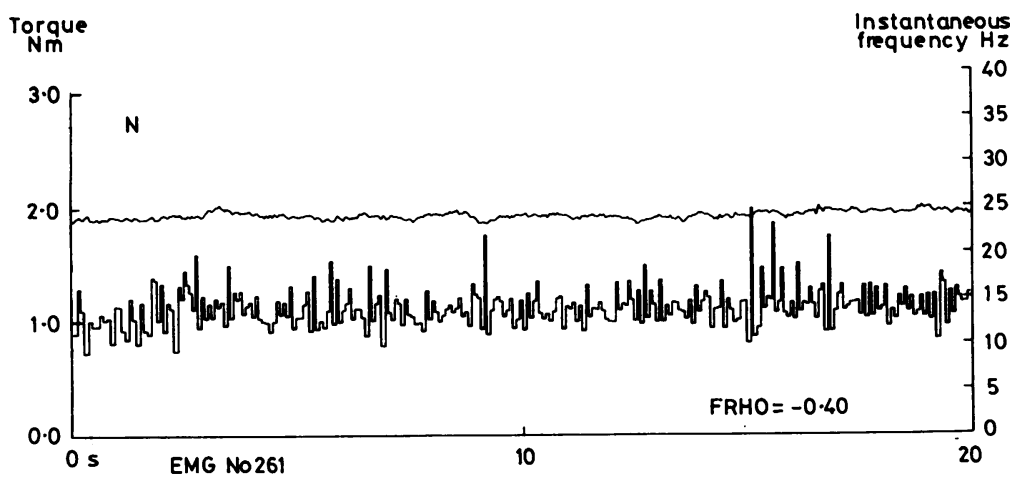

Fig 3 Torque around the ankle joint and instantaneous frequency over a $20 \mathrm{~s}$ period in a normal subject $(N)$ and in a patient with spasticity $(P)$. In each plot the upper curve is torque around the ankle joint $(\mathrm{Nm})$ and the lower curve is instantaneous frequency $\mathrm{(Hz}$. FRHO is the floating serial correlation coefficient of successive intervals. Normal

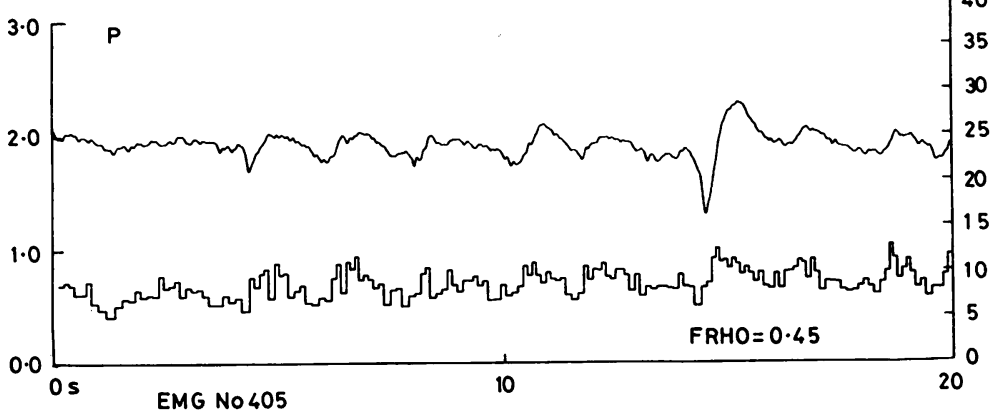
subject, MD female 16 years old. Patient with spasticity, IB female 56 years old.

double discharges observed in one third of the recordings from muscles of normal subjects were rarely found in the patients with spasticity. The variability in intervals was described by FSD, VAR and VARI. ${ }^{13}$ As in normal subjects, FSD and VARI increased with the mean interval. In the patients with spasticity FSD tended to fall below the normal regression line (fig 5). This was even more pronounced for the values of VARI (fig 6). One patient with multiple sclerosis (GA) was an exception. In this patient all values of FSD and VARI fell above the regression line in normal subjects. The fluctuations in torque were the same as in other patients $(10-50 \%)$, the level of contraction was low $1 \cdot 5-10 \%$ of $\mathrm{T}_{\max }$, and the mean intervals were shorter than in the other patients.

The serial correlation between intervals was previously described by plotting the joint interval histograms and by calculating the serial correlation coefficient RHO.1 16-19

In patients a short interval was followed by a short and a long interval by a long corresponding to a positive slope of the long axis of the contour ellipse in the joint interval histogram (fig 7, right). In normal subjects the slope of the long axis in the joint interval histograms was negative. A source of error is a slow change in frequency during the 1 ccording period. This could change a negative to a positive slope (Andreassen and Rosenfalck, ${ }^{13}$ fig 6 ). A positive slope in the joint interval histogram is equivalent to a positive value of the serial correlation coefficient RHO. To avoid this error and to obtain a quantitative expression for the serial correlation between intervals a floating serial correlation coefficient FRHO was calculated relative to a "floating mean interval." FRHO increased with the mean interval as in normal subjects (fig 8).

In patients with cerebral lesions (Groups P1 and P2) $95 \%$ of the values of FRHO fell above the regression line for normal subjects, while the patients with spinal involvement (group P3) had normal values of FRHO. It may be argued that the increase in FRHO was due to the fluctuations in firing rate. If this was so FRHO should increase with the magnitude of the fluctuations. This was not found. When FRHO was plotted as a function of the size of the fluctuations in torque, there was no correlation. In addition there was no significant correlation between FRHO and the level of torque at which the recording was obtained.

In fig 9 the values of VAR and FRHO were plotted, ignoring the dependence of VAR and FRHO on the mean interval. Freund et $a l^{6}$ 

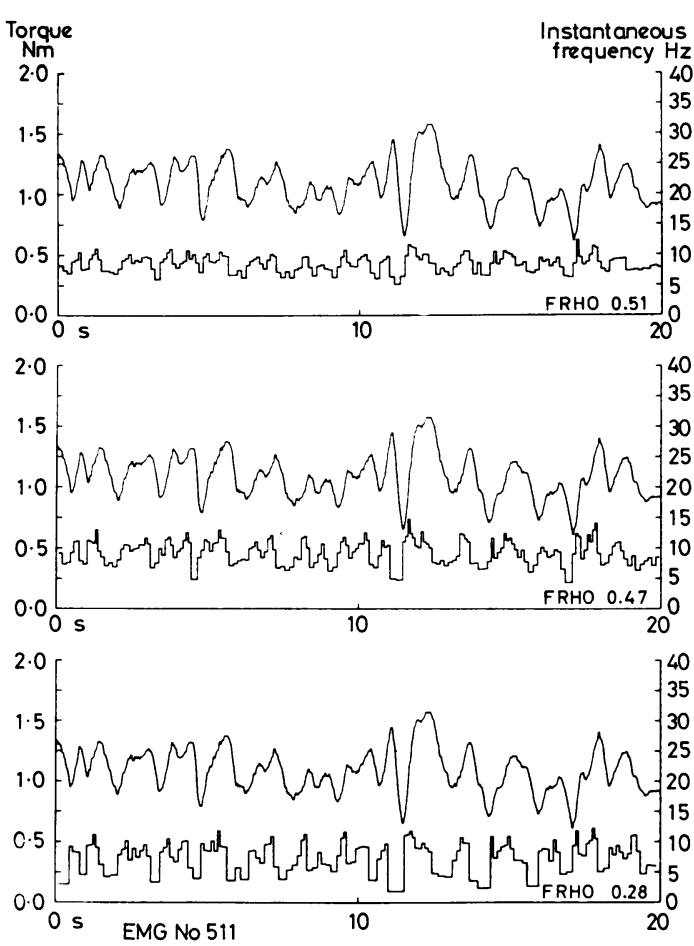

Fig 4 Torque around the ankle joint and instantaneous frequency over a $20 \mathrm{~s}$ period for three different motor units extracted from the same recording. Patient with spasticity $M H$, male 59 vears old. mentioned that " not all units recorded from one patient are similarly involved; some of them show the characteristic pattern, others do not or only weakly." This observation was confirmed in this study in the respect that most of the patients had some motor units, where VAR and FRHO fell within the normal range. It is therefore necessary to analyse several motor units in each patient, preferably 10 or more. However, the width of the histograms of VAR is not increased for the individual patients, when compared to the width of the histograms for individual normal subjects, and the width of the histograms for FRHO is only slightly increased for the patients. It is therefore likely that the firing pattern of all motor units in a patient is approximately equally affected, giving a shift in the mean values of the VAR and FRHO parameters, without a significant increase in the width of the histograms. If some motor units had been affected, while others had remained normal an increased scatter of the parameters VAR and FRHO would have been expected. The hypothesis, that the motor units are approximately equally affected, is also supported by the similar behaviour observed in motor units recorded simultaneously (fig 4).

Double discharges The double discharges observed during maintained contraction in one third of the motor units from muscles of normal subjects were rarely found in the patients with
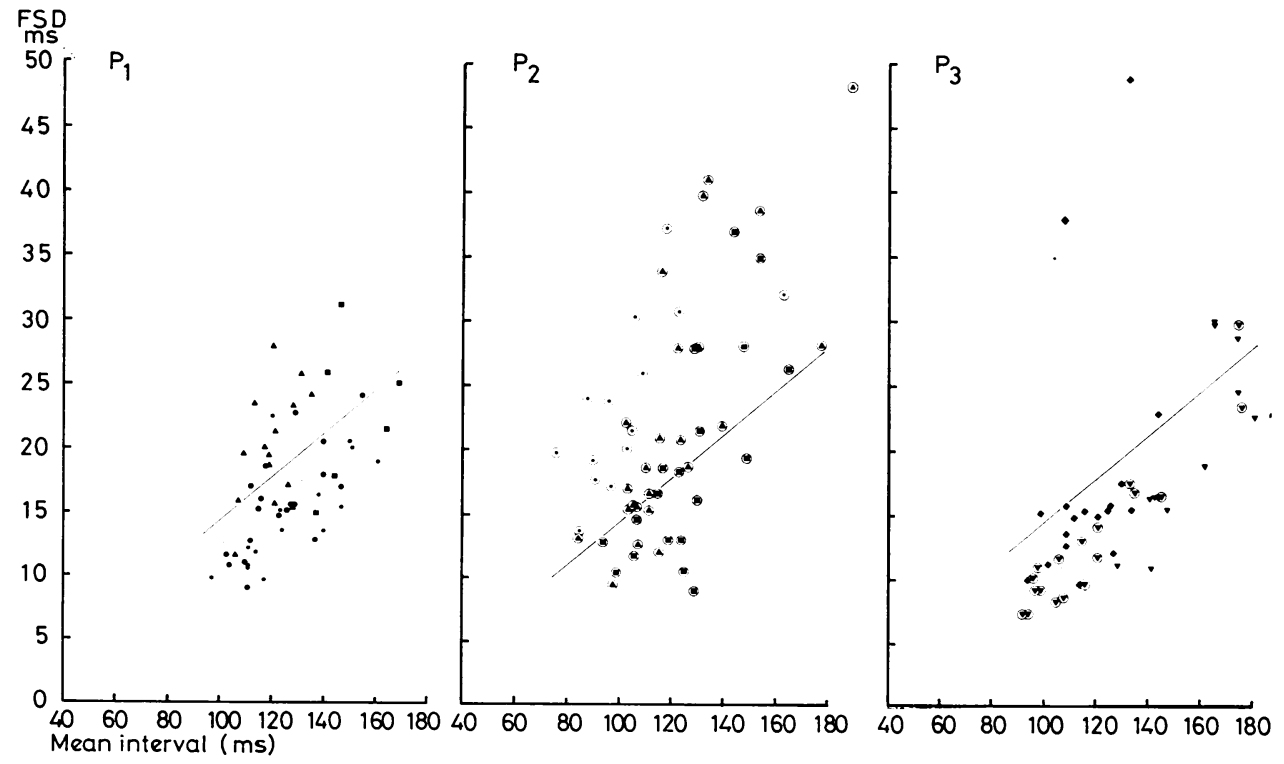

Fig 5 Floating standard deviation FSD as a function of mean interval. 160 recordings from single motor units in 10 patients with spasticity. $P_{1}: M H \triangle, E P \bigcirc, A P \bullet, I N \square ; P_{2}: I B \bigcirc, P G \circlearrowleft, G A \odot ; P_{3}: B A \oslash, N F \nabla, S G \diamond$. 


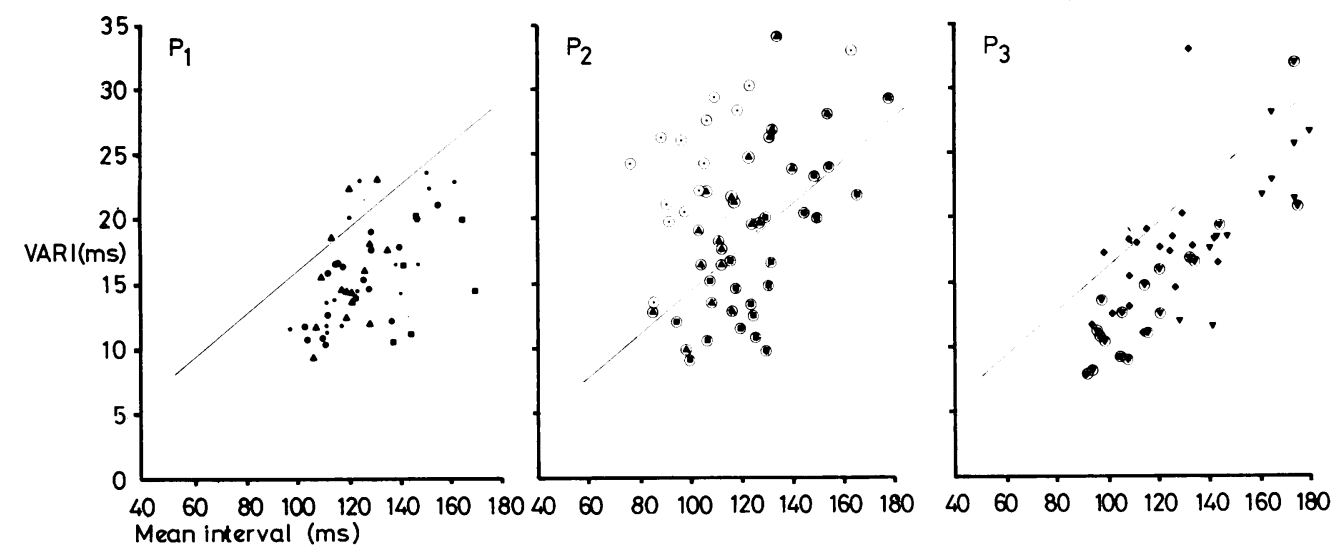

Fig 6 Short term variation in instantaneous frequency VARI as a function of mean interval. Recordings from single motor units in 10 patients with spasticity. $P_{1}: M H \triangle, E P \bullet, A P \bullet, I N \backsim ; P_{2}: I B \odot, P G \oplus, G A \odot ; P_{3}: B A \oplus, N F \nabla, S G \diamond$.
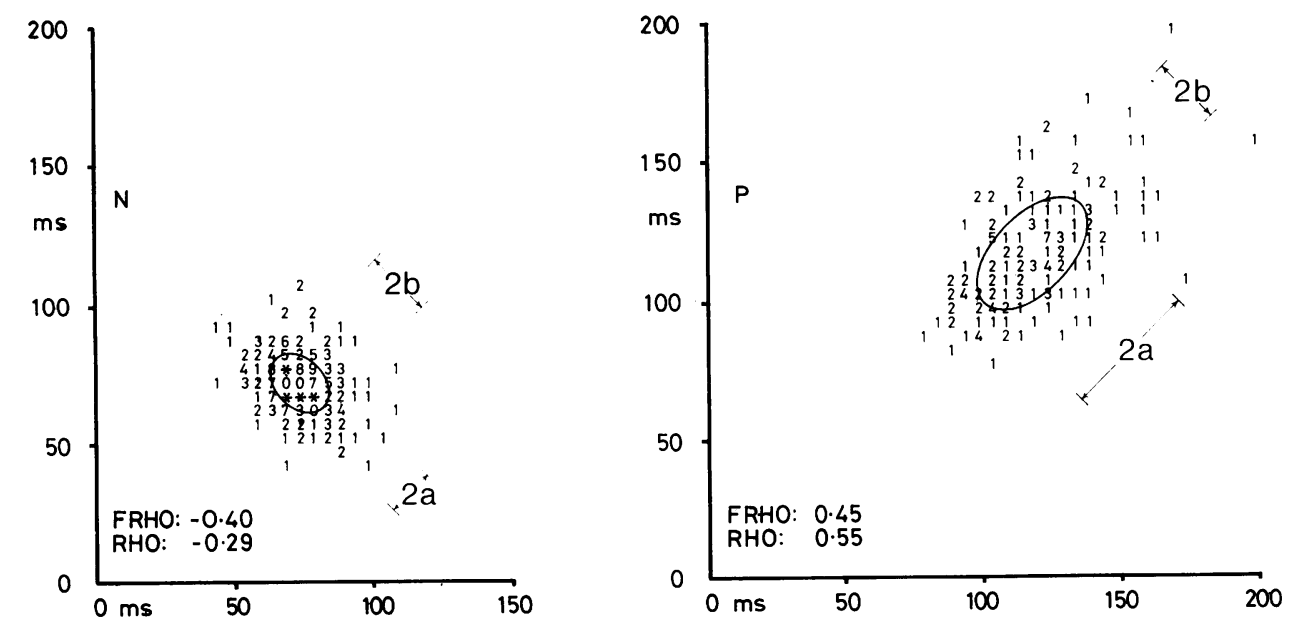

Fig 7 Joint interval histograms for a normal subject $(N)$ and for a patient with spasticity $(P)$. In the normal subject $(N)$ axis a of the contour ellipse is smaller than axis b corresponding to a negative serial correlation coefficient $R H O(a=9 \mathrm{~ms}$, $b=12 \mathrm{~ms})$. In the patient with spasticity axis $a$ is greater than axis $b$ and $R H O$ positive $(a=25 \mathrm{~ms}, b=13 \mathrm{~ms})$. The floating serial correlation coefficient FRHO is 0.1 smaller than RHO in both plots due to the negative bias when calculating relative to a floating mean of 19 intervals. ${ }^{13}$ Same recordings as fig 3.
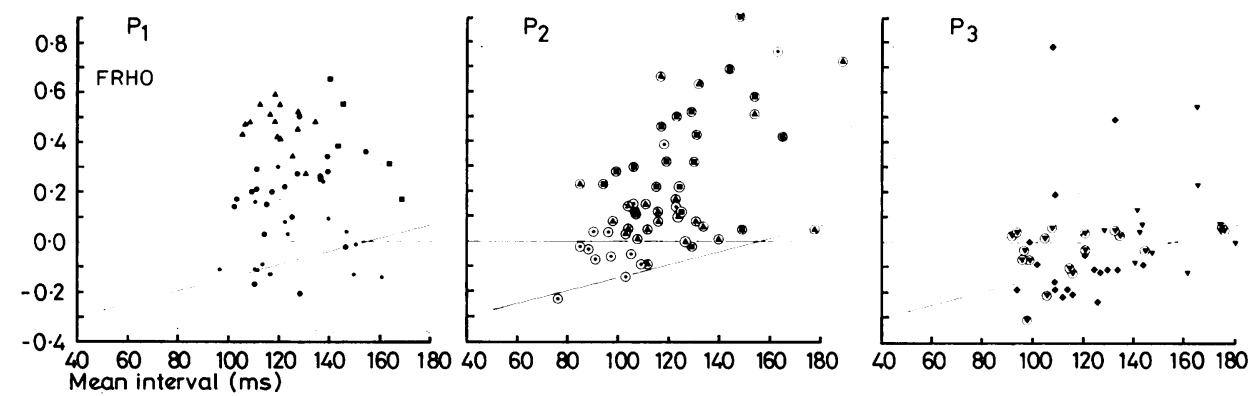

Fig 8 Floating serial correlation coefficient FRHO between successive intervals as a function of mean interval. Recordings from single motor units in 10 patients with spasticity. $P_{1}: M H \triangle, E P \odot, A P \bullet, I N \square ; P_{2}: I B \oplus, P G \Theta, G A \odot$; $P_{3}: B A \nabla, N F \nabla, S G \diamond$. 


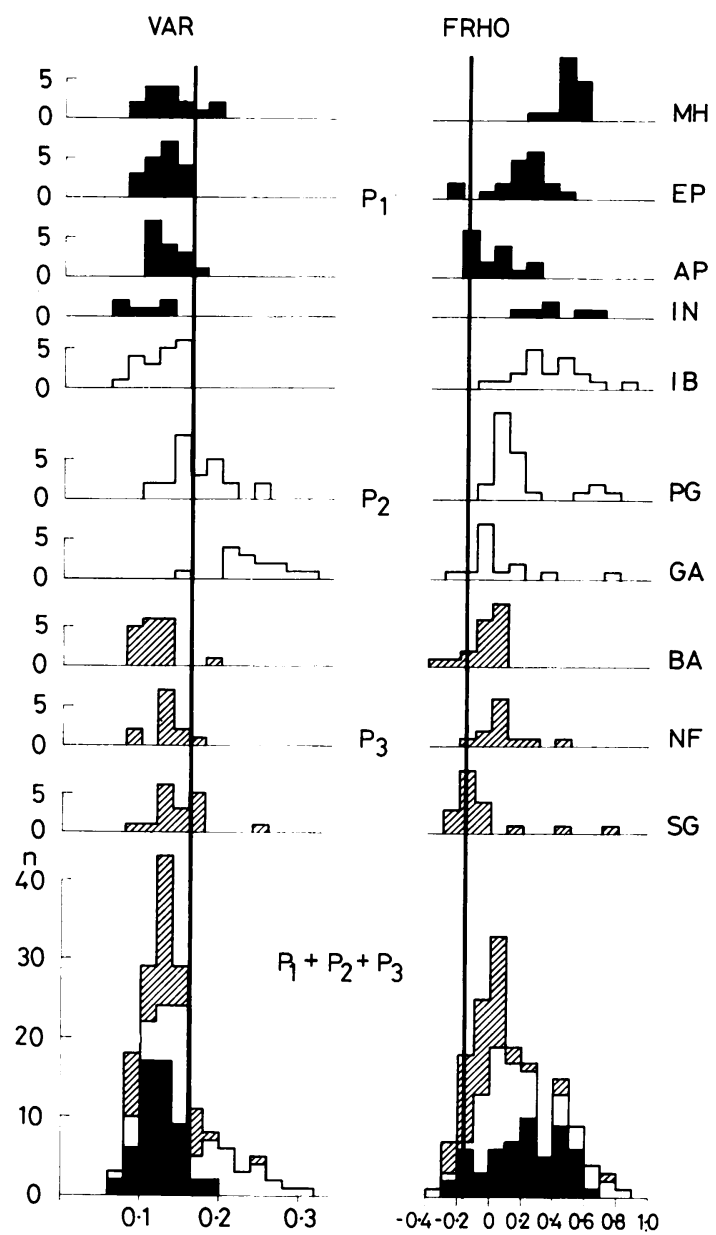

Fig 9 Histograms for $V A R$ and FRHO for 160 motor units recorded from 10 patients with spasticity. $n$ : number of motor units. Below data pooled from the 10 patients $P_{1}+P_{2}+P_{3}$

spasticity. Double discharges were rarely found at the onset of a contraction, where they are frequently found in normal subjects. This is in accordance with the observation that the patients were unable to correct changes in torque quickly.

\section{Discussion}

The torque recorded in patients with spasticity differed in two respects from normal: maximal torque was $40 \%$ or less of that in normal subjects; during submaximal contraction the fluctuations in torque were larger and slower than in normal subjects.
The reduction in force in hemiparetic patients has been attributed to different causes: disuse atrophy, vascular changes, arthropathy, $\alpha$-motoneurone degeneration, pressure neuropathy, and an unspecified parietal mechanism (for references see McComas et al $^{22}$ ). The present finding of a reduced firing rate in patients with spasticity (fig 1) suggests that the torque is lower than normal, partly because most motor units fire at a rate where they produce unfused twitches. Similar reductions in firing rate were previously found in patients with upper motoneurone disease ${ }^{23}$ and in Parkinsonism. ${ }^{123}{ }^{24}$

One might turn the question around and ask if the reduction of firing frequency is simply a consequence of the low torque. Considering the plot of torque in $\mathrm{NNm}$ and mean interval (fig 2A) this could be the case as the points fall around the regression line for the normal subjects. However, there are a number of motor units firing regularly at mean intervals above $160 \mathrm{~ms}$, which is rarely found in normal subjects. Furthermore if each patient is used as his own reference, and the torque is plotted in per cent of his maximal torque, $\mathrm{T}_{\max }$ (fig $2 \mathrm{~B}$ ), the majority of the points fall above the regression line for normal subjects indicating a reduction of firing frequencies. This presentation of the data is justified if disuse atrophy is considered a major reason for the reduced torque. It is also justified if the antagonists were cocontracting. The antagonists were not monitored during voluntary contractions and cocontraction could have been present, even though the patients could relax both agonists and antagonists at rest.

The reduced firing rates could be due to a change in membrane properties of the motor neurons, for example increased duration of the after hyperpolarisation. It could also be due to a bias in the sampling of motor units towards slow twitch units, which can fire continuously at low rates. The bias may be caused by preferential atrophy of fast twitch muscle fibres, ${ }^{25}$ or the patients may be unable to recruit the fast twitch motor units.

The fluctuations in torque were reflected in the firing pattern. We found similar changes in the firing pattern in all motor units examined (figs 3 and 4). The fluctuations in instantaneous frequency preceded the fluctuations in torque by $100 \mathrm{~ms}-500 \mathrm{~ms}$. Even though the torque fluctuated more than normal, the short term variation between intervals was less than normal in the patients with spasticity. The large variation between successive intervals and the negative values of FRHO found in the normal subjects 
was suggested to be an expression of a feedback mechanism that keeps the torque constant by fast corrections of the frequency. ${ }^{13}$ In the patients with spasticity this mechanism was impaired and the instantaneous frequency drifted up and down. The reduced variability was previously found in hand muscles of patients with spasticity ${ }^{3}$ and in patients with cerebellar lesions. ${ }^{6}$ Poor utilisation of feedback from muscle receptors could explain the lack of fast control and the corresponding fluctuations in torque. This is in accordance with the enhancement of low frequency tremor (below $8 \mathrm{~Hz}$ ) in the masseter muscle of monkey after deafferentation. ${ }^{26}$ In man, Burke et $a l^{27}$ recorded from single muscle spindle afferents in the peroneal nerve during slow shortening of the anterior tibial muscle and showed that feedback from spindles may control irregularities in the shortening. The hypothesis of poor utilisation of peripheral feedback is consistent with the finding that the second EMG burst M2 in response to a sudden perturbation of the thumb ${ }^{28} 29$ is absent when the long loop reflexes are disturbed by lesions in the afferent or efferent branches. The increase in the modified serial correlation between successive intervals FRHO which we have found in the patients with spasticity can be interpreted the same way.

Cocontraction of the antagonist creates a "myotatic unit," where afferent input from the antagonist increases the efficiency of the reflex regulation of the firing pattern. If cocontraction were present in the patients an increased regulation of the firing pattern would be expected, thus making the present finding of a reduction of the regulation more striking.

\section{"Phasic" and "tonic" motor units}

In the 160 motor units classified from 122 recordings from patients with spasticity we never observed disturbances in the recruitment order as described by Grimby et al. ${ }^{11} 12$ They found that "phasic" units are recruited as "tonic" units fatigue. Usually we did not attempt to continue the recording until the patients fatigued and this could account for our inability to confirm their finding. The $20 \mathrm{~s}$ recording periods used for analysis were however selected from 1-4 min recordings in the normal subjects and in the patients with spasticity. In these longer recordings we failed to find motor units firing in high frequency bursts corresponding to the firing pattern of the "phasic" motor units found in normal subjects $^{3031}$ and in patients with spasticity.1112 In the present study units recorded a high levels of contraction showed the same firing pattern as other units. We found in accordance with Clamann, ${ }^{32}$ Gillies, ${ }^{33}$ Tanji and Kato ${ }^{34}$ and Gydikov and Kosarov 35 that the firing rate of "tonic" motor units with low recruitment threshold could be increased considerably during increasing contraction. Grimby and Hannerz ${ }^{30}$ and Borg et al, ${ }^{31}$ have not included force recordings in their illustrations of the firing pattern, this makes the interpretation of a "phasic" firing pattern uncertain. None of the data in the present study (firing rate, VAR and FRHO) distinguish between "tonic" and "phasic" units. This is in accordance with other investigations of the firing pattern in normal subjects ${ }^{2036}$ which failed to confirm the original finding by Tokizane and Shimazu ${ }^{37}$ that "tonic" and "phasic" units can be distinguished by their firing pattern. When two or three motor units were extracted from the same recording they behaved similarly (fig 4), with respect both to long term and short term fluctuations. The similar behaviour of all motor units in individual normal subjects and in individual patients with spasticity also was confirmed by the finding of the narrow width of the histograms of VAR and FRHO (fig 9).

\section{Distinction between spinal and supraspinal}

lesions

In patients with cerebral lesions $95 \%$ of the values for FRHO fell above the normal regression line. The increase in serial correlation coefficient FRHO was less pronounced in the patients with spinal involvement. Whether the changes in VAR and FRHO can be used to localise the site of the lesion needs further investigation of patients with well-defined lesions in the central nervous system.

We are indebted to the Department of Neurology at the Rigshospital for referring patients under their care. We thank Professor F Buchthal for helpful criticism during the work and in the preparation of the manuscript. The work was initiated at the Institute of Neurophysiology, University of Copenhagen and at the Electronics Institute, Technical University of Denmark. The study was supported by the Danish Medical Research Council and by the Danish Council for Scientific and Industrial Research.

\section{References}

1 Dietz V, Hillesheimer W, Freund HJ. Correlation between tremor, voluntary contraction and firing pattern of motor units in Parkinson's disease. J Neurol Neurosurg Psychiatry 1974; 37:927-37. 
2 Kranz H. Discharge characteristics of motoneurones. International Symposium on human reflexes and motor disorders. Desmedt JE, ed. Bruxelles: 113 bis, 1976.

$3 \mathrm{Kranz} \mathrm{H}$. Dynamic aspects of motoneurone control and its disturbance. In: Desmedt $\mathbf{J}$, ed. Progress in Clinical Neurophysiology, vol 9. 1979.

4 Andreassen S, Rosenfalck A. Impaired regulation of the firing pattern of single motor units. Muscle and Nerve 1978; 1:416-8.

5 Rosenfalck A, Andreassen S. Firing pattern of individual motor unit potentials during voluntary effort. In: Asmussen EH, Jørgensen $\mathrm{K}$, eds. Biomechanics, $I V-A$. Baltimore: University Park Press, 1978: 183-97.

6 Freund HJ, Dietz V, Wita CW, Kapp H. Discharge characteristics of single motor units in normal subjects and patients with supraspinal motor disturbances. In: Desmedt J, ed. New Developments in Electromyography and Clinical Neurophysiology 1973; 3:242-50.

7 Henneman E, Somjen G, Carpenter DO. Functional significance of cell size in spinal motoneurones. J Neurophysiol 1965; 28:560-80.

8 Tanji J, Kato M. Recruitment of motor units in voluntary contraction of a finger muscle in man. Exp Neurol 1973; 40:759-70.

9 Milner-Brown HS, Stein RB, Yemm R. The orderly recruitment of human motor units during voluntary contraction of muscle. J Physiol (Lond) 1973; 230:359-70.

10 Büdingen $\mathrm{HJ}$, Freund $\mathrm{HJ}$. The relationship between the rate of rise of isometric tension and motor unit recruitment in a human forearm muscle. Pfügers Archiv 1976; 362:61-7.

11 Grimby L. Hannerz J. Rånlund T. Disturbances in the voluntary recruitment order of anterior tibial motor units in spastic paraparesis upon fatigue. J Neurol Neurosurg Psychiatry 1974; 37: 40-6.

12 Grimby L, Hannerz J. Disturbances in the voluntary recruitment order of anterior tibial motor units in ataxia. J Neurol Neurosurg Psychiatry 1975; 38:46-51.

13 Andreassen S, Rosenfalck A. Regulation of the firing pattern of single motor units. J Neurol Neurosurg Psychiatry 1980; 43:897-906.

14 Andreassen S, Rosenfalck A. Recording from a single motor unit during strong effort. IEEE Transactions on Biomedical Engineering, $B M E$ 25,$1978 ; 501-8$.

15 Asmussen E, Heebøll-Nielsen K. Isometric muscle strength of adult men and women. Danish National Association for Infantile Paralysis (Polio). Communication 11, 1961.

16 Andreassen S. Interval pattern of single motor units. PhD thesis revised. Aalborg University Press, 1978: 1-220.

17 Freund HJ, Wita CW. Computeranalyse des Intervallmusters einzelner motorischer Einheiten bei Gesunden und Patienten mit supraspinalen motorischen Störungen. Arch Psychiat Nerven- krank 1971; 214:56-71.

18 Person RS, Kudina LP. Discharge frequency and discharge pattern of human motor units during voluntary contraction of muscle. Electroencephalogr Clin Neurophysiol 1972; 32:471-83.

19 Freund HJ, Wita CW, Sprung C. Discharge properties and functional differentiation of single motor units in man. In: Somjen CG, ed. Neurophysiology studied in man. Amsterdam: Excerpta Medica, 1972: 305-13.

20 Freund HJ, Büdingen HJ, Dietz V. Activity of single motor units from human forearm muscles during voluntary isometric contractions. J Neurophysiol 1975; 38:933-46.

21 Burke D, Schiller HH. Discharge pattern of single motor units in the tonic vibration reflex of human triceps surae. J Neurol Neurosurg Psychiatry 1976; 39:729-41.

22 McComas AJ, Sica REP, Upton ARM, Aguilera N. Functional changes in motoneurones of hemiparetic patients. J Neurol Neurosurg Psychiatry 1973; 36:183-93.

23 Das Gupta A. Behaviour of single motor units in human skeletal muscle. PhD thesis. University of Edinburgh, 1962.

24 Milner-Brown HS, Fisher MA, Weiner WJ. Electrical properties of motor units in Parkinsonism and a possible relationship with bradykinesia. J Neurol Neurosurg Psychiatry 1979; 42: $35-41$.

25 Chokroverty S, Reyes MG, Rubino FA, Barron KD. Hemiplegic amyotrophy. Arch Neurol 1976; 33:104-10.

26 Goodwin GM, Hoffman D, Luschei ES. The strength of the reflex response to sinosoidal stretch of monkey jaw closing muscles during voluntary contraction. J Physiol 1978; 279: 81-111.

27 Burke D, Hagbarth KE, Löfstedt L. Muscle spindle responses in man to changes in load during accurate position maintenance. $J$ Physiol 1978; 276:159-64.

28 Lee RG, Tatton WG. Motor response to sudden limb displacements in primates with specific CNS lesions and in human patients with motor system disorders. Can J Neurol Sci 1975; 2:285-93.

29 Marsden CD, Merton PA, Morton HB, Adam J. The effect of posterior column lesions on servo responses from the human long thumb flexor. Brain 1977; 100:185-200.

30 Grimby L, Hannerz J. Firing rate and recruitment order of toe extensor motor units in different modes of voluntary contraction. J Physiol 1977; 264:865-79.

31 Borg J, Grimby L, Hannerz J. Axonal conduction velocity and voluntary discharge properties of individual short toe extensor motor units in man. J Physiol 1978; 277:143-52.

32 Clamann HP. Statistical analysis of motor unit firing pattern in human skeletal muscle. Biophys $J$ 1969; 9:1233-51.

33 Gillies JD. Motor unit discharge patterns during 
isometric contraction in man. J Physiol 1972; 223:36-7P.

34 Tanji J, Kato M. Firing rate of individual motor units in voluntary contraction of abductor digiti minimi muscle in man. Exp Neurol 1973; 40: 771-83.

35 Gydikov A, Kosarov D. Some features of different motor units in human biceps brachii.
Pfügers Archiv 1974; 347:75-88.

36 Desmedt JE, Godaux E. Ballistic contractions in man: characteristic recruitment pattern of single motor units of the tibialis anterior muscle. $J$ Physiol 1977; 264:673-93.

37 Tokizane T, Shimazu H. Functional differentiation of human skeletal muscle. Tokyo: University of Tokyo Press, 1964. 